\title{
Comparação da vegetação arbórea e características edáficas de um cerradão e um cerrado sensu stricto em áreas adjacentes sobre solo distrófico no leste de Mato Grosso, Brasil ${ }^{1}$
}

\author{
Ben Hur Marimon Junior ${ }^{2,4}$ e Mundayatan Haridasan ${ }^{3}$
}

Recebido em 10/09/2004. Aceito em 07/06/2005

\begin{abstract}
RESUMO - (Comparação da vegetação arbórea e características edáficas de um cerradão e um cerrado sensu stricto em áreas adjacentes em solos distróficos no leste de Mato Grosso, Brasil). Em alguns casos, cerrado sensu stricto e cerradão ocorrem lado a lado e sob condições edáficas e topográficas semelhantes. Como os fatores que contribuem para a ocorrência de cerradão nessas situações ainda não estão totalmente esclarecidos, o objetivo do presente estudo foi comparar a composição florística e a fitossociologia de um cerradão e um cerrado sensu stricto no leste mato-grossense e verificar se maior fertilidade do solo estava contribuindo para a ocorrência do cerradão. Em cada comunidade foi realizado um levantamento florístico e fitossociológico em 50 parcelas de $10 \mathrm{~m} \times 10 \mathrm{~m}$, onde foram medidas todas as árvores com diâmetro maior do que $5 \mathrm{~cm}$ a $30 \mathrm{~cm}$ do solo. Foram coletadas amostras de solos de um perfil de $2 \mathrm{~m}$ de profundidade em cada área e amostras superficiais $(0-10$ e 10-20 cm). As fitofisionomias foram distintas quanto a florística, estrutura e fitossociologia. A área basal $\left(21,4 \mathrm{~m}^{2} \mathrm{ha}^{-1}\right)$ e altura média $(6,4 \mathrm{~m})$ do cerradão foram maiores do que as do cerrado sensu stricto $\left(14,9 \mathrm{~m}^{2}\right.$ ha ${ }^{-1}$ e 3,7 m). No cerradão, as três espécies mais importantes foram Hirtella glandulosa Spreg., Sclerolobium paniculatum Vog. e Xylopia aromatica (Lam.) Mart., somando 29\% do Índice do Valor de Importância (IVI) total e no cerrado sensu stricto, foram Qualea parviflora Mart., Davilla elliptica A. St.-Hil. e Roupala montana Aubl., somando 20,5 do IVI total. Os solos sob ambas as fitofisionomias foram ácidos $(\mathrm{pH}<5,0)$ e distróficos $\left(\mathrm{Ca}^{2+}<0,4 \mathrm{cmol}_{\mathrm{c}} \mathrm{kg}^{-1}\right)$, com altos teores de alumínio trocável $\left(\mathrm{Al}^{3+}>1,3 \mathrm{cmol}_{\mathrm{c}} \mathrm{kg}^{-1}\right)$. A fertilidade do solo não apresentou diferenças para corroborar a hipótese de que a ocorrência do cerradão ao lado do cerrado sensu stricto era devida à maior fertilidade do solo. O solo sob o cerradão apresentou textura mais argilosa em todo o perfil, o que pode significar maior disponibilidade de água para as árvores durante todo o ano. Esse é um aspecto que merece investigações no futuro.
\end{abstract}

Palavras-chave : Savana, fitossociologia, fitofisionomia, fertilidade do solo

\begin{abstract}
A comparison of the woody vegetation and soil characteristics of a cerradão and a Cerrado sensu stricto in adjacents areas on dystrophic soils in eastern Mato Grosso State, Brazil). Cerrado sensu stricto and cerradão often occur side by side under similar edaphic and topographic conditions. The factors which contribute to the existence of cerradão in this situation are not well established. The objective of the present study was to compare the floristic composition and phytosociology of a Cerrado and cerradão on a dystrophic soil in eastern Mato Grosso and to determine whether higher soil fertility was contributing to the existence of the cerradão. Fifty $10 \mathrm{~m} \times 10 \mathrm{~m}$ plots were laid out in each vegetation type and a phytosociological survey was conducted of all trees with a minimum diameter of $5 \mathrm{~cm}$ at $30 \mathrm{~cm}$ above ground level. Soil samples were collected up to a depth of $2 \mathrm{~m}$ of soil profiles and from surface layer $(0-10$ and $10-20 \mathrm{~cm})$ in each area. The two physiognomies showed distinct floristic, structural and phytosociological characteristics. The basal area $\left(21.4 \mathrm{~m}^{2}\right.$ ha $\left.{ }^{-1}\right)$ and the mean heights $(6.4 \mathrm{~m})$ of the cerradão were greater than that of the cerrado sensu stricto $\left(14.9 \mathrm{~m}^{2}\right.$ ha-1 and $\left.3.7 \mathrm{~m}\right)$. The three most important species were Hirtella glandulosa Spreg., Sclerolobium paniculatum Vog. and Xylopia aromatica (Lam.) Mart. in the cerradão, representing 29\% of the total Importance Value (IVI), and Qualea parviflora Mart., Davilla elliptica A. St.-Hil. and Roupala montana Aubl. in the cerrado sensu stricto, representing $21 \%$ of the total IVI. The soils of both areas were acid $(\mathrm{pH}<5.0)$ and dystrophic $\left(\mathrm{Ca}^{2+}<0.4 \mathrm{cmol}_{\mathrm{c}} \mathrm{kg}^{-1}\right)$ with high exchangeable aluminium levels $\left(\mathrm{Al}^{3+}>1.3 \mathrm{cmol}_{\mathrm{c}} \mathrm{kg}^{-1}\right)$. The fertility of the soils of the two areas was not different to support the hypothesis that the occurrence of the cerradão was due to the higher fertility of its soil. However, the cerradão soil showed higher percentages of clay than the cerrado soil at all depths up to $2 \mathrm{~m}$, which could result in a higher availability of water throughout the year for the trees. This is an aspect worth investigating in future studies.
\end{abstract}

Key words: Savanna, phytosociology, phytophysiognomy, soil fertility

\footnotetext{
1 Parte da Dissertação de Mestrado do primeiro Autor

2 Universidade do Estado de Mato Grosso, BR-158, Km 145, CEP 70690-000, Nova Xavantina, MT, Brasil

3 Universidade de Brasília, Instituto de Biologia, Departamento de Ecologia, Brasília, DF

4 Autor para correspondência: benhur@unb.br
} 


\section{Introdução}

O Bioma Cerrado brasileiro, com grande diversidade de formas fitofisionômicas, ocorre em 15 estados e o Distrito Federal, ocupando uma área de aproximadamente dois milhões de $\mathrm{km}^{2}$, a qual corresponde a um quarto da superfície do país. A forma mais extensa, o cerrado sensu stricto, ocupava aproximadamente $65 \%$ da área geográfica do Bioma, enquanto que o cerradão ocupava apenas cerca de $1 \%$. No restante da área original $(34 \%)$, diversos outros tipos fitofisionômicos dividiam a paisagem.

A distribuição e a manutenção das diferentes fitofisionomias do Bioma Cerrado estão relacionadas com fatores edáficos e topográficos, além da ocorrência de fogo e perturbações antrópicas (Eiten 1972; RADAMBRASIL 1981; Oliveira-Filho et al. 1990). A profundidade efetiva, a drenagem, a presença de concreções no perfil, a profundidade do lençol freático e a fertilidade do solo são considerados os principais fatores determinantes da diversidade fitofisionômica (Eiten 1972; Haridasan 1992). O cerrado sensu stricto é uma vegetação savânica composta por um estrato arbóreo-arbustivo e outro herbáceo-graminoso (Eiten 1994). Normalmente, ocorre sobre Latossolos e Neossolos Quartzarênicos profundos, bem drenados, distróficos, ácidos e álicos e raramente sobre solos mesotróficos (Haridasan 1992). O cerradão é uma vegetação florestal que ocorre tanto em solos distróficos quanto mesotróficos, sendo sua composição florística variável conforme a fertilidade do solo (Ratter 1971; Ratter et al. 1973; 1977; Araújo \& Haridasan 1988).

Os fatores determinantes do cerradão ainda não estão totalmente esclarecidos. Segundo Goodland (1971a; b) e Lopes \& Cox (1977), a sua ocorrência estaria relacionada a um gradiente de fertilidade dos solos, onde o cerradão estaria ocupando sítios de fertilidade mais acentuada, mas não o suficiente para serem considerados solos mesotróficos. Ratter (1971) e Ratter et al. (1973) reconheceram duas situações distintas no leste de Mato Grosso, onde um tipo de cerradão estaria relacionado a solos de alta fertilidade e outro a solos de baixa fertilidade, o qual denominaram "cerradão de Hirtella glandulosa". Ribeiro \& Haridasan (1984) identificaram no Bioma Cerrado a ocorrência de cerradão em solos de fertilidade tão baixa quanto de cerrado sensu stricto. Costa \& Araújo (2001), trabalhando em um cerrado sensu stricto e um cerradão adjacentes no Triângulo Mineiro, também verificaram que ambos ocorriam em solos distróficos, com nível de fertilidade, $\mathrm{pH}$ e teores de $\mathrm{Al}$ muito semelhantes.

Na Reserva Biológica Mário Viana, no leste de Mato Grosso, o cerradão ocorre em manchas adjacentes ao cerrado sensu stricto sob condições topográficas bastante semelhantes. O solo sob ambas as fitofisionomias não possui concreções ou qualquer outro tipo de impedimento, bem como nenhuma evidência de proximidade do lençol freático à superfície. O objetivo do presente estudo foi comparar a composição florística e a fitossociologia dessas duas vegetações e determinar se a ocorrência do cerradão está associada a uma maior fertilidade do solo.

\section{Material e métodos}

As fitofisionomias estudadas localizam-se na Reserva Biológica Municipal Mário Viana (14²41'S e $52^{\circ} 20^{\prime} \mathrm{W}$ ), município de Nova Xavantina, leste do estado de Mato Grosso. É uma região de transição entre o bioma cerrado e a floresta amazônica, onde a vegetação predominante de cerrado sensu stricto está em contato com extensas áreas de matas e manchas de cerradão. A altitude média da reserva é de $250 \mathrm{~m}$, o relevo é plano a suave-ondulado e os solos predominantes são Latossolo Vermelho-Amarelo e Latossolo Amarelo, na maioria distróficos, álicos, profundos, bem drenados e de textura média, com material de origem da Cobertura Sedimentar do Bananal (RADAMBRASIL 1981). O clima é do tipo Aw de Köppen, (Camargo 1963), com precipitação média anual de $1.600 \mathrm{~mm}$ (Nimer 1989) e temperatura média anual de $24,4^{\circ} \mathrm{C}$ (Fig. 1).

Foram estabelecidas em cada área 50 parcelas de $10 \times 10 \mathrm{~m}(0,5 \mathrm{ha})$ para o levantamento fitossociológico. Foram medidos o diâmetro e a altura

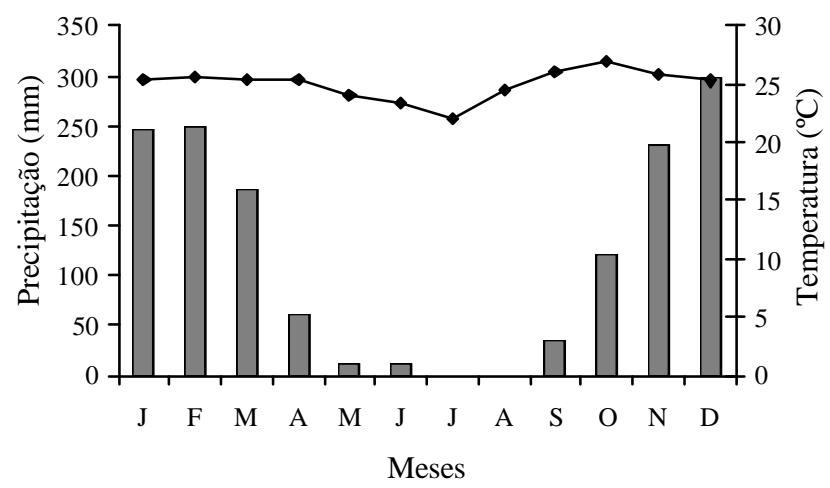

Figura 1. Precipitação e temperaturas médias na Reserva Mário Viana em Nova Xavantina, MT, Brasil. Dados médios de 1995 a 2000 obtidos na Estação Meteorológica da UNEMAT. 
das árvores, vivas e mortas, com diâmetro mínimo de $5 \mathrm{~cm}$ na altura de $30 \mathrm{~cm}$ do solo. A diversidade florística das duas comunidades foi calculada pelo índice de Shannon, sendo que a uniformidade (ou equabilidade) foi verificada pelo índice de Pielou. Para avaliar a similaridade florística entre as duas comunidades foi utilizado o índice de Sørensen e de Morisita (Horn 1966).

Para comparação das propriedades do solo, foi aberto um perfil em cada fitofisionomia e retiradas amostras em sete profundidades: $0-15 ; 15-30 ; 30-45$; 45-70; 70-100; 100-140 e 140-200 cm. Para determinar as variações do solo dentro das fitofisionomias, foram selecionadas 25 parcelas aleatórias em cada área e escolhidos dois pontos aleatórios em cada parcela para coletas de amostras compostas nas profundidades de 0-10 e 10-20 cm. A textura foi determinada através do método de Bouyoucos; o $\mathrm{pH}$ foi medido em água e em $\mathrm{KCl}\left(1 \mathrm{~mol} \mathrm{~L}^{-1}\right)$; o teor de $\mathrm{N}$ total foi obtido pelo método de Kjeldahl; o teor de matéria orgânica pelo método de Walkey-Black; os teores de Ca, $\mathrm{Mg}$ e $\mathrm{Al}$ trocáveis foram obtidos em $\mathrm{KCl}$ a $1 \mathrm{~mol} \mathrm{~L}^{-1}$ e os teores de $\mathrm{P}$ e $\mathrm{K}$ no extrato de Mehlich $\left(\mathrm{H}_{2} \mathrm{SO}_{4}\right.$ a $0,01251 \mathrm{~mol} \mathrm{~L}^{-1}$; $\mathrm{HCl}$ a 0,051 mol L-1) (Tan 1996). O alumínio foi determinado por titulação com $\mathrm{NaOH}$, o fósforo por colorimetria utilizando-se molibdato de amônia e ácido ascórbico (3\%) e os demais por espectrofotometria de absorção atômica e emissão de chama (Allen 1974).

\section{Resultados e discussão}

Florística e fitossociologia - As espécies mais importantes no cerradão foram, por ordem de IVI, $H$. glandulosa (41,7), Sclerolobium paniculatum $(24,2)$, Xylopia aromatica $(20,8)$, Eriotheca gracilipes $(11,5)$ e Emmotum nitens $(11,4)$, as quais representaram $36,5 \%$ do IVI total. No cerrado sensu stricto foram Qualea parviflora $(27,8)$, Davilla elliptica $(19,9)$, Roupala montana $(13,8)$, Syagrus flexuosa $(11,2)$ e Qualea grandiflora $(11,1)$, representando $28 \%$ do IVI total. Os principais gêneros e espécies amostrados evidenciam o padrão florístico típico observado para cerrado sensu stricto em outras áreas e/ou Estados (Ribeiro et al. 1985; Furley et al. 1988; Nascimento \& Saddi 1992; Oliveira-Filho et al. 1990; Marimon et al. 1998; Costa \& Araújo 2001; P.E. Nogueira, dados não publicados). A composição florística do cerradão enquadrou-se no tipo descrito por Ratter et al. (1973) como "cerradão de Hirtella glandulosa", em função da espécie de maior IVI. A composição de espécies difere da encontrada por Ribeiro \& Haridasan (1984) em um cerradão em Planaltina, DF, onde Emmotum nitens, Ocotea spixiana e Sclerolobium paniculatum var. rubiginosum foram as espécies mais importantes. As diferenças são ainda maiores em relação ao cerradão amostrado por Costa \& Araújo (2001) em Uberlândia, MG, onde as espécies de maior IVI foram Qualea grandiflora, Vochysia tucanorum e Matayba guianensis.

Foi encontrado o mesmo número de espécies no cerrado sensu stricto e no cerradão (77), sendo que apenas uma do cerrado (Ficus sp.) não foi identificada. A curva espécies $\times$ área foi semelhante em ambas as comunidades; $87 \%$ de todas as espécies do levantamento, tanto para o cerrado sensu stricto quanto para o cerradão, foram encontradas na primeira metade $\left(2.500 \mathrm{~m}^{2}\right)$ das 50 parcelas (Fig. 2). Assim, a área total de amostragem $\left(5.000 \mathrm{~m}^{2}\right)$ foi suficiente para a comparação da composição florística e da estrutura das fitofisionomias.

As duas fitofisionomias mostraram-se distintas quanto a composição florística, diâmetro médio, altura e área basal (Tab. 1). O cerradão apresentou indivíduos que atingiram mais de 14 metros de altura, dossel fechado e um padrão tipicamente florestal, com presença de cipós e vegetação graminosa-herbácea muito rara (Fig. 3). A área basal foi $21,4 \mathrm{~m}^{2} \mathrm{ha}^{-1}$, sendo que, deste total, 67,3\% refere-se às dez espécies mais importantes (Tab. 2). A espécie Hirtella glandulosa, de maior IVI, participa com 23,6\% da área basal total. O cerrado sensu stricto apresentou padrão tipicamente savânico, com estrato herbáceo-graminoso abundante e espécies que atingiram altura máxima de 7,5 metros (Fig. 4). A área basal foi de $14,9 \mathrm{~m}^{2} \mathrm{ha}^{-1}$, sendo $46 \%$ referente às dez espécies mais importantes e $11,7 \%$ à Qualea parviflora, espécie de maior IVI (Tab. 3).

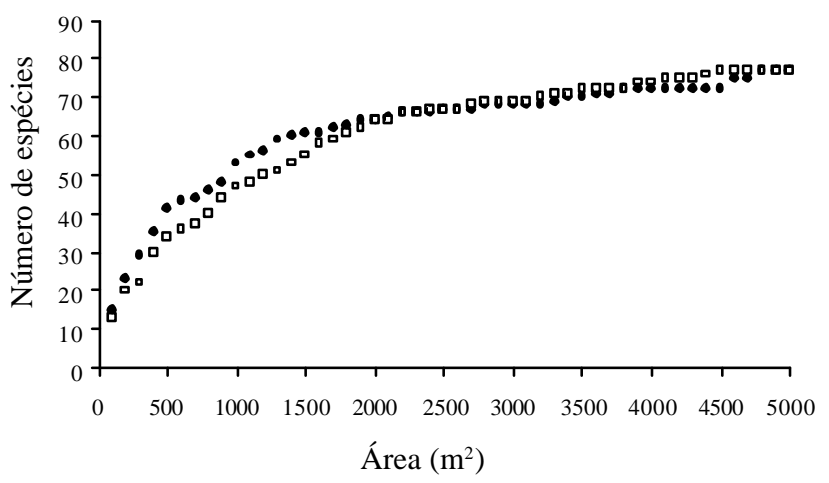

Figura 2. Curva espécies $\times$ área (curva do coletor) do cerrado sensu stricto e do cerradão na Reserva Mário Viana, Nova Xavantina, MT, Brasil. $\bullet=$ Parc. 1 a 50 - Cerrado sensu stricto; $\square=$ Parc. 1 a 50 - Cerrado. 
Tabela 1. Características fitossociológicas do cerrado sensu stricto na Reserva Mário Viana, Nova Xavantina, MT, Brasil.

\begin{tabular}{|c|c|c|}
\hline Características & $\begin{array}{l}\text { Cerrado } \\
\text { sensu stricto }\end{array}$ & Cerradão \\
\hline Área amostral (hectares) & 0,5 & 0,5 \\
\hline Número de espécies & 77 & 77 \\
\hline Espécies exclusivas & 32 & 32 \\
\hline Espécies comuns & & \\
\hline Número de famílias & 38 & 36 \\
\hline Famílias exclusivas & 11 & 9 \\
\hline Famílias comuns & & \\
\hline Índice de diversidade de Shannon (H') & 3,78 & 3,67 \\
\hline Equabilidade de Pielou & 0,87 & 0,84 \\
\hline Densidade (árvores/ha) & 1.890 & 1.884 \\
\hline Área Basal (m²/ha) & 14,94 & 21,37 \\
\hline Altura média (m) & 3,71 & 6,35 \\
\hline Altura máxima(m) & 10,50 & 16,50 \\
\hline
\end{tabular}

A distribuição dos diâmetros apresentou diferenças inerentes às duas comunidades (Fig. 5). O cerrado sensu stricto apresentou maior número de indivíduos com diâmetros menores do que $10 \mathrm{~cm}$, enquanto que o cerradão apresentou maior número de indivíduos acima de $10 \mathrm{~cm}$ de diâmetro. A distribuição dos diâmetros nas duas comunidades apresentou a forma de J-invertido, sendo que mais de $50 \%$ dos indivíduos apresentaram-se com diâmetro inferior a $10 \mathrm{~cm}$. Este padrão indica que o cerrado sensu stricto e o cerradão são fitofisionomias autoregenerativas (Felfili \& SilvaJúnior 1988). A distribuição das alturas foi quase unimodal nas duas comunidades (Fig. 6), ajustando-se ao que foi observado por Felfili (1997) para uma distribuição natural.

As áreas basais de ambas as comunidades mostraram-se maiores do que as encontradas por diversos autores no Bioma Cerrado. Felfili et al. (1993), comparando onze áreas de cerrado sensu stricto das Chapadas Pratinha e dos Veadeiros, encontraram valores para cerrado sensu stricto que variaram entre 5,8 e $11,3 \mathrm{~m}^{2} \mathrm{ha}^{-1}$. Costa \& Araújo (2001) encontraram $17,1 \mathrm{~m}^{2} \mathrm{ha}^{-1}$ para um cerradão e $9,63 \mathrm{~m}^{2} \mathrm{ha}^{-1}$ para um cerrado sensu stricto em Uberlândia-MG, enquanto que Felfili et al. (2002) encontraram 7,5 $\mathrm{m}^{2} \mathrm{ha}^{-1} \mathrm{em}$ um cerrado sensu stricto em Água Boa, MT. A área

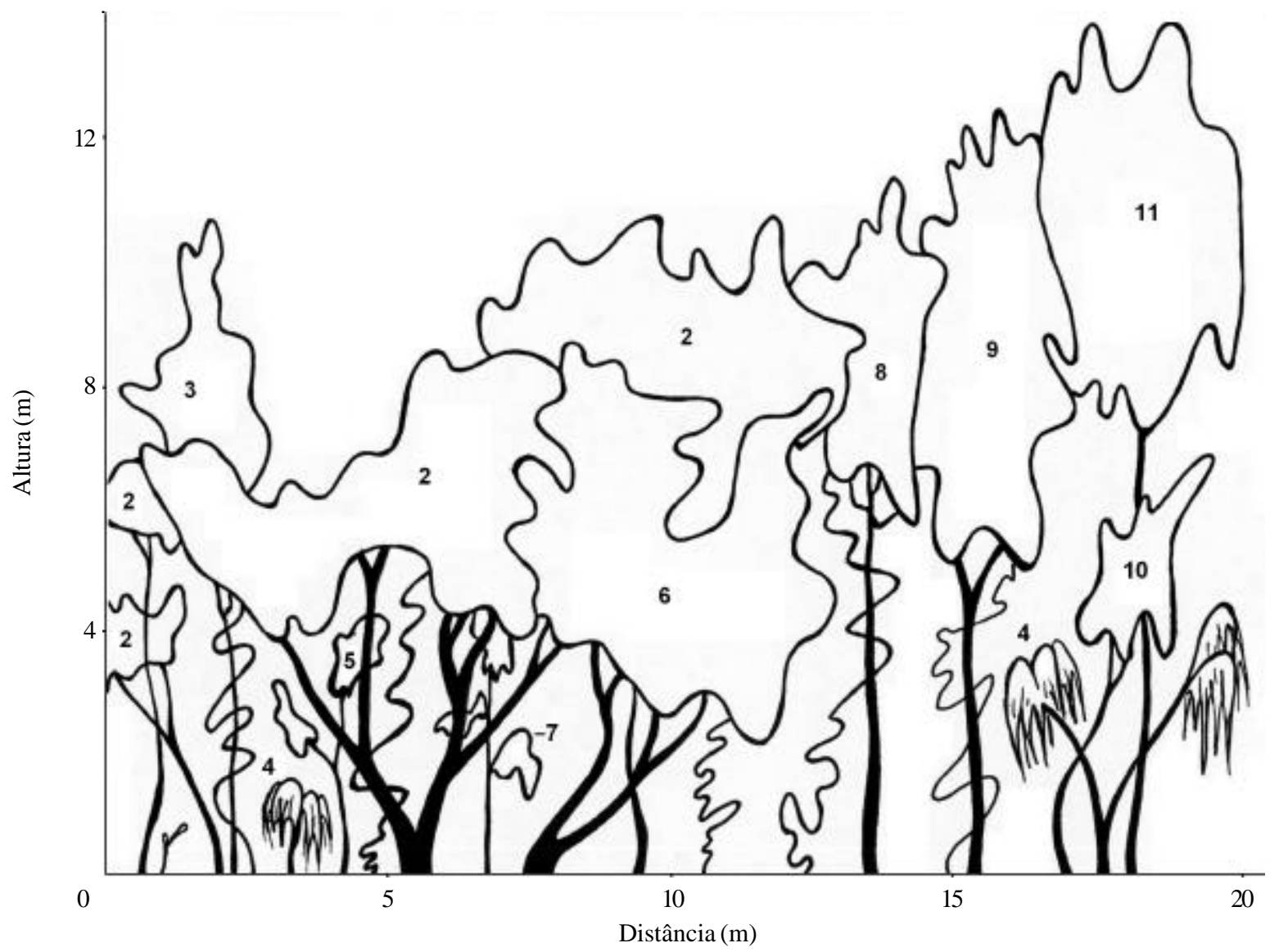

Figura 3. Perfil esquemático do cerradão na Reserva Mário Viana, Nova Xavantina, MT, Brasil. Espécies: 1 - Vatairea macrocarpa; 2 - Hirtella glandulosa; 3 - Lutzelburgia praecox; 4 - Syagrus flexuosa; 5 - Erythroxylum daphnites; 6 - Myrcia sellowiana; 7 - Hirtella gracilipes; 8 - Curatella americana; 9 - Protium heptaphyllum; 10 - Terminalia argentea; 11 - Sclerolobium paniculatum. 
Tabela 2. Parâmetros fitossociológicos das espécies arbóreas do cerrado sensu stricto da Reserva Municipal Mário Viana, Nova Xavantina, MT, Brasil. $\mathrm{Ni}=$ número de indivíduos; $\mathrm{DR}=$ Densidade relativa; $\mathrm{FA}=$ Freqüência absoluta; $\mathrm{FR}=$ Frquiência relativa; Doa $=$ Dominância absoluta; DoR = dominância relativa; IVI = Índice do Valor de Importância; IVC = Índice do Valor de Cobertura.

\begin{tabular}{|c|c|c|c|c|c|c|c|c|}
\hline Espécies & $\mathrm{Ni}$ & DR & FA & FR & DoA & DoR & IVC & IVI \\
\hline Hirtella glandulosa Spreng. & 112 & 11,89 & 41 & 6,24 & 5,042 & 23,59 & 35,48 & 41,72 \\
\hline Sclerolobium paniculatum Vog. & 61 & 6,48 & 31 & 4,72 & 2,778 & 13,00 & 19,47 & 24,19 \\
\hline Xylopia aromatica (Lam.) Mart. & 71 & 7,54 & 38 & 5,78 & 1,604 & 7,51 & 15,04 & 20,83 \\
\hline Eriotheca gracilipes (K. Schum.) A. Robyns & 31 & 3,29 & 21 & 3,20 & 1,071 & 5,01 & 8,30 & 11,50 \\
\hline Emmotum nitens (Benth.) Miers. & 24 & 2,55 & 19 & 2,89 & 1,260 & 5,89 & 8,44 & 11,33 \\
\hline Guapira graciliflora (Mart. ex Schmidt) Lund & 46 & 4,88 & 28 & 4,26 & 0,449 & 2,10 & 6,99 & 11,25 \\
\hline Roupala montana Aubl. & 39 & 4,14 & 25 & 3,81 & 0,693 & 3,25 & 7,39 & 11,19 \\
\hline Myrcia sellowiana Berg & 41 & 4,35 & 25 & 3,81 & 0,545 & 2,55 & 6,90 & 10,71 \\
\hline Aspidosperma multiflorum A. DC. & 34 & 3,61 & 25 & 3,81 & 0,545 & 2,55 & 6,16 & 9,97 \\
\hline Matayba guianensis Aubl. & 28 & 2,97 & 21 & 3,20 & 0,388 & 1,82 & 4,79 & 7,99 \\
\hline Hirtella gracilipes (Hook. f.) Prance & 29 & 3,08 & 20 & 3,04 & 0,270 & 1,26 & 4,34 & 7,39 \\
\hline Heisteria ovata Benth. & 27 & 2,87 & 20 & 3,04 & 0,236 & 1,11 & 3,97 & 7,02 \\
\hline Tapirira guianensis Aubl. & 19 & 2,02 & 12 & 1,83 & 0,422 & 1,98 & 3,99 & 5,82 \\
\hline Mezilaurus crassiramea (Meissn.) Taub. & 11 & 1,17 & 10 & 1,52 & 0,620 & 2,90 & 4,07 & 5,59 \\
\hline Vatairea macrocarpa (Benth.) Ducke & 19 & 2,02 & 15 & 2,28 & 0,249 & 1,17 & 3,18 & 5,47 \\
\hline Guapira noxia (Netto) Lund & 19 & 2,02 & 12 & 1,83 & 0,265 & 1,24 & 3,26 & 5,08 \\
\hline Pseudobombax longiflorum (Mart. \& Zucc.) A. Robyns & 15 & 1,59 & 12 & 1,83 & 0,323 & 1,51 & 3,11 & 4,93 \\
\hline Erythroxylum daphnites Mart. & 17 & 1,80 & 14 & 2,13 & 0,122 & 0,57 & 2,38 & 4,51 \\
\hline Protium heptaphyllum (Aubl.) March. & 14 & 1,49 & 12 & 1,83 & 0,224 & 1,05 & 2,54 & 4,36 \\
\hline Alibertia elliptica (Cham.) K. Schum. & 15 & 1,59 & 13 & 1,98 & 0,119 & 0,56 & 2,15 & 4,13 \\
\hline Antonia ovata Pohl & 14 & 1,49 & 12 & 1,83 & 0,102 & 0,48 & 1,96 & 3,79 \\
\hline Luetzelburgia praecox (Harms.) Harms. & 10 & 1,06 & 9 & 1,37 & 0,287 & 1,34 & 2,40 & 3,77 \\
\hline Sorocea klotzchiana Baill & 13 & 1,38 & 12 & 1,83 & 0,093 & 0,44 & 1,82 & 3,65 \\
\hline Terminalia argentea Mart. \& Zucc. & 10 & 1,06 & 9 & 1,37 & 0,241 & 1,13 & 2,19 & 3,56 \\
\hline Syagrus flexuosa $\mathrm{L}$. & 15 & 1,59 & 10 & 1,52 & 0,089 & 0,42 & 2,01 & 3,53 \\
\hline Alchornea schomburgkii Klotz & 12 & 1,27 & 11 & 1,67 & 0,116 & 0,55 & 1,82 & 3,49 \\
\hline Agonandra brasiliensis Benth. \& Hook. f. & 9 & 0,96 & 6 & 0,91 & 0,185 & 0,87 & 1,82 & 2,74 \\
\hline Ouratea spectabilis (Mart.) Engl. & 9 & 0,96 & 9 & 1,37 & 0,052 & 0,25 & 1,20 & 2,57 \\
\hline Pterodon pubescens (Benth.) Benth. & 5 & 0,53 & 4 & 0,61 & 0,299 & 1,40 & 1,93 & 2,54 \\
\hline Annona coriacea Mart. & 9 & 0,96 & 7 & 1,07 & 0,107 & 0,50 & 1,46 & 2,52 \\
\hline Curatella americana $\mathrm{L}$. & 5 & 0,53 & 5 & 0,76 & 0,227 & 1,06 & 1,59 & 2,36 \\
\hline Aspidosperma macrocarpon Mart. & 7 & 0,74 & 7 & 1,07 & 0,113 & 0,53 & 1,27 & 2,34 \\
\hline Salvertia convallariaeodora St. Hil. & 9 & 0,96 & 7 & 1,07 & 0,063 & 0,30 & 1,25 & 2,32 \\
\hline Alibertia edulis (L.C. Rich.) A. Rich. ex DC. & 7 & 0,74 & 7 & 1,07 & 0,048 & 0,22 & 0,97 & 2,03 \\
\hline Qualea parviflora Mart. & 7 & 0,74 & 6 & 0,91 & 0,072 & 0,34 & 1,08 & 2,00 \\
\hline Coccoloba mollis Casar & 8 & 0,85 & 5 & 0,76 & 0,080 & 0,38 & 1,23 & 1,99 \\
\hline Qualea multiflora Mart. & 6 & 0,64 & 6 & 0,91 & 0,086 & 0,40 & 1,04 & 1,95 \\
\hline Syagrus comosa (Mart.) Becc. & 7 & 0,74 & 5 & 0,76 & 0,095 & 0,45 & 1,19 & 1,95 \\
\hline Maprounea guianensis (Aubl.) M. Arg. & 6 & 0,64 & 6 & 0,91 & 0,067 & 0,31 & 0,95 & 1,86 \\
\hline Dipteryx alata Vog. & 4 & 0,42 & 4 & 0,61 & 0,174 & 0,82 & 1,24 & 1,85 \\
\hline Siparuna guianensis Aubl. & 6 & 0,64 & 6 & 0,91 & 0,062 & 0,29 & 0,93 & 1,84 \\
\hline Euplassa inaequalis (Pohl) Engl. & 5 & 0,53 & 5 & 0,76 & 0,111 & 0,52 & 1,05 & 1,81 \\
\hline Dimorphandra mollis Benth. & 6 & 0,64 & 5 & 0,76 & 0,084 & 0,40 & 1,03 & 1,79 \\
\hline Qualea grandiflora Mart. & 6 & 0,64 & 6 & 0,91 & 0,051 & 0,24 & 0,88 & 1,79 \\
\hline Vochysia rufa Mart. & 5 & 0,53 & 5 & 0,76 & 0,091 & 0,43 & 0,96 & 1,72 \\
\hline Lacistema aggregatum (Berg.) Rusby & 6 & 0,64 & 6 & 0,91 & 0,028 & 0,13 & 0,77 & 1,68 \\
\hline Astronium fraxinifolium Schott. & 4 & 0,42 & 4 & 0,61 & 0,094 & 0,44 & 0,87 & 1,48 \\
\hline Strychnos pseudoquina A. St.-Hil. & 2 & 0,21 & 2 & 0,30 & 0,204 & 0,96 & 1,17 & 1,47 \\
\hline Eugenia geminiflora $\mathrm{O}$. Berg & 5 & 0,53 & 5 & 0,76 & 0,037 & 0,18 & 0,71 & 1,47 \\
\hline Machaerium acutifolium Vog. & 4 & 0,42 & 4 & 0,61 & 0,037 & 0,17 & 0,60 & 1,21 \\
\hline Styrax camporum Pohl & 3 & 0,32 & 3 & 0,46 & 0,065 & 0,31 & 0,63 & 1,08 \\
\hline Vochysia haenkeana Mart. & 2 & 0,21 & 2 & 0,30 & 0,092 & 0,43 & 0,64 & 0,95 \\
\hline Tabebuia aurea (Manso) Benth. \& Hook. f. ex S. Moore & 3 & 0,32 & 3 & 0,46 & 0,032 & 0,15 & 0,47 & 0,93 \\
\hline Brosimum gaudichaudii Tréc. & 3 & 0,32 & 3 & 0,46 & 0,031 & 0,15 & 0,47 & 0,92 \\
\hline Andira vermifuga Mart. ex Benth. & 3 & 0,32 & 3 & 0,46 & 0,022 & 0,11 & 0,42 & 0,88 \\
\hline
\end{tabular}


Tabela 2 (continuação)

\begin{tabular}{|c|c|c|c|c|c|c|c|c|}
\hline Espécies & $\mathrm{Ni}$ & DR & FA & FR & DoA & DoR & IVC & IVI \\
\hline Byrsonima coccolobifolia H.B. \& K. & 2 & 0,21 & 2 & 0,30 & 0,062 & 0,29 & 0,51 & 0,81 \\
\hline Hymenaea stigonocarpa Mart. ex Hayne & 3 & 0,32 & 2 & 0,30 & 0,023 & 0,11 & 0,43 & 0,73 \\
\hline Tetrapterys glabra (Spreng.) Griseb & 2 & 0,21 & 2 & 0,30 & 0,037 & 0,17 & 0,39 & 0,69 \\
\hline Copaifera langsdorffii Desf. & 2 & 0,21 & 2 & 0,30 & 0,025 & 0,12 & 0,33 & 0,63 \\
\hline Dalbergia miscolobium Benth. & 2 & 0,21 & 2 & 0,30 & 0,024 & 0,11 & 0,33 & 0,63 \\
\hline Bowdichia virgilioides H.B. \& K. & 2 & 0,21 & 2 & 0,30 & 0,022 & 0,11 & 0,32 & 0,62 \\
\hline Plathymenia reticulata Benth. & 2 & 0,21 & 2 & 0,30 & 0,015 & 0,07 & 0,28 & 0,59 \\
\hline Couepia grandiflora (Mart. \& Zucc.) Benth. \& Hook. f. & 2 & 0,21 & 2 & 0,30 & 0,014 & 0,07 & 0,28 & 0,59 \\
\hline Tapura amazonica Poepp. \& Endl. & 2 & 0,21 & 2 & 0,30 & 0,014 & 0,07 & 0,28 & 0,58 \\
\hline Mimosa laticifera Rizzini \& Mattos & 2 & 0,21 & 2 & 0,30 & 0,011 & 0,05 & 0,27 & 0,57 \\
\hline Cardiopetalum calophyllum Schlecht. & 2 & 0,21 & 2 & 0,30 & 0,010 & 0,05 & 0,26 & 0,57 \\
\hline Ficus sp. & 2 & 0,21 & 2 & 0,30 & 0,009 & 0,04 & 0,26 & 0,56 \\
\hline Platypodium elegans Vog. & 1 & 0,11 & 1 & 0,15 & 0,056 & 0,26 & 0,37 & 0,52 \\
\hline Simarouba amara Aubl. & 1 & 0,11 & 1 & 0,15 & 0,049 & 0,23 & 0,34 & 0,49 \\
\hline Magonia pubescens A. St.-Hil. & 1 & 0,11 & 1 & 0,15 & 0,032 & 0,15 & 0,26 & 0,41 \\
\hline Andira cuiabensis Benth. & 1 & 0,11 & 1 & 0,15 & 0,022 & 0,11 & 0,21 & 0,37 \\
\hline Cybistax antisiphilitica (Mart.) Mart. & 1 & 0,11 & 1 & 0,15 & 0,019 & 0,09 & 0,20 & 0,35 \\
\hline Peltogyne confertiflora (Hayne) Benth. & 1 & 0,11 & 1 & 0,15 & 0,011 & 0,06 & 0,16 & 0,31 \\
\hline Miconia albicans (Sw.) Triana & 1 & 0,11 & 1 & 0,15 & 0,007 & 0,04 & 0,14 & 0,29 \\
\hline Byrsonima basiloba A. Juss. & 1 & 0,11 & 1 & 0,15 & 0,005 & 0,03 & 0,13 & 0,29 \\
\hline Myrcia camapuanensis N.F.E. Silveira & 1 & 0,11 & 1 & 0,15 & 0,005 & 0,03 & 0,13 & 0,28 \\
\hline \multirow[t]{2}{*}{ Aspidosperma nobile M. Arg. } & 1 & 0,11 & 1 & 0,15 & 0,004 & 0,02 & 0,13 & 0,28 \\
\hline & 942 & 100 & 1.314 & 100 & 21,377 & 100 & 200 & 300 \\
\hline
\end{tabular}

basal por hectare do cerradão foi cerca de 1,4 vezes superior à do cerrado sensu stricto e a altura média em torno de 1,7 vezes, o que sugere maior biomassa do cerradão em relação ao cerrado sensu stricto. A participação de $H$. glandulosa no total dessa biomassa é duas vezes maior do que a participação de $Q$. parviflora no total do cerrado sensu stricto. Essas diferenças evidenciam um padrão estrutural distinto

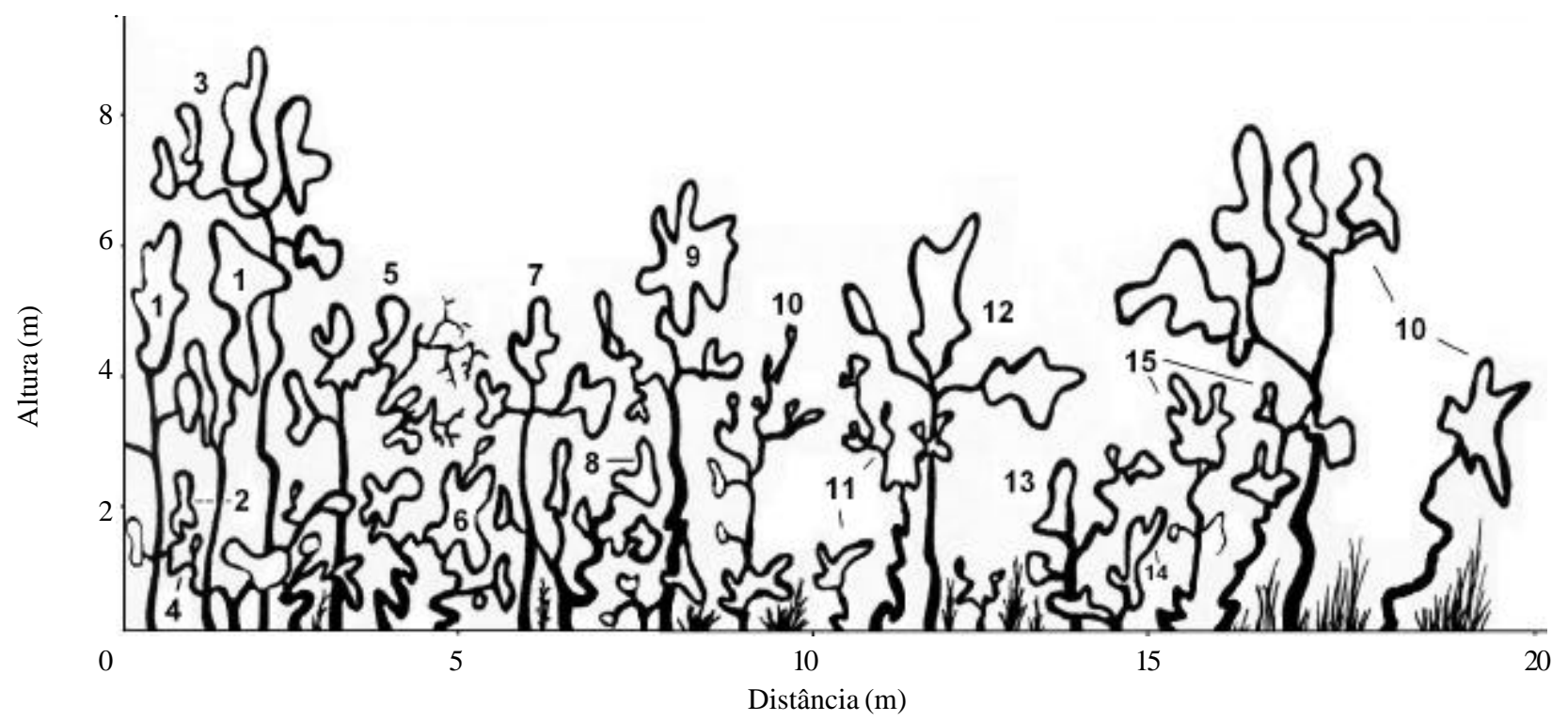

Figura 4. Perfil esquemático do cerrado sensu stricto na Reserva Mário Viana, Nova Xavantina, MT, Brasil. Espécies: 1 - Euplassa inaequalis; 2 - Qualea multiflora; 3 - Curatella americana; 4 - Davilla elliptica; 5 - Hymenaea stigonocarpa; 6 - Myrcia lanuginosa; 7 - Emmotun nitens; 8 - Guapira noxia; 9 - Magonia pubescens; 10 - Roupala montana; 11 - Lafoensia pacari; 12 - Aspidosperma tomentosum; 13 - Qualea grandiflora; 14 - Erythroxylum suberosum; 15 - Caryocar brasiliense. 
Tabela 3. Parâmetros fitossociológicos das espécies arbóreas do cerradão da Reserva Municipal Mário Viana, Nova Xavantina, MT, Brasil. $\mathrm{Ni}=$ número de indivíduos; $\mathrm{DR}=$ Densidade relativa; $\mathrm{FA}=$ Freqüência absoluta; $\mathrm{FR}=$ Frqüência relativa; Doa $=$ Dominância absoluta; DoR = dominância relativa; IVI = Índice do Valor de Importância; IVC = Índice do Valor de Cobertura.

\begin{tabular}{|c|c|c|c|c|c|c|c|c|}
\hline Espécies & $\mathrm{Ni}$ & DR & FA & FR & DoA & DoR & IVC & IVI \\
\hline Qualea parviflora Mart. & 103 & 10,90 & 40 & 5,81 & 1,668 & 11,17 & 22,07 & 27,88 \\
\hline Davilla elliptica A. St.-Hil. & 73 & 7,72 & 40 & 5,81 & 0,956 & 6,40 & 14,13 & 19,94 \\
\hline Roupala montana Aubl. & 37 & 3,92 & 21 & 3,05 & 1,025 & 6,86 & 10,78 & 13,83 \\
\hline Syagrus flexuosa L. & 44 & 4,66 & 25 & 3,63 & 0,438 & 2,93 & 7,59 & 11,22 \\
\hline Qualea grandiflora Mart. & 34 & 3,60 & 23 & 3,34 & 0,626 & 4,19 & 7,79 & 11,13 \\
\hline Aspidosperma tomentosum Mart. & 28 & 2,96 & 24 & 3,49 & 0,463 & 3,10 & 6,06 & 9,55 \\
\hline Vochysia rufa Mart. & 26 & 2,75 & 20 & 2,91 & 0,377 & 2,53 & 5,28 & 8,19 \\
\hline Kielmeyera rubriflora Camb. & 24 & 2,54 & 20 & 2,91 & 0,406 & 2,72 & 5,26 & 8,17 \\
\hline Euplassa inaequalis (Pohl) Engl. & 15 & 1,59 & 13 & 1,89 & 0,684 & 4,58 & 6,17 & 8,06 \\
\hline Byrsonima crassa Nied. & 30 & 3,17 & 22 & 3,20 & 0,238 & 1,59 & 4,77 & 7,97 \\
\hline Myrcia lanuginosa DC. & 31 & 3,28 & 20 & 2,91 & 0,193 & 1,29 & 4,57 & 7,48 \\
\hline Ouratea hexasperma (A. St.-Hil.) Bail. & 26 & 2,75 & 16 & 2,33 & 0,306 & 2,05 & 4,80 & 7,13 \\
\hline Magonia pubescens A. St.-Hil. & 24 & 2,54 & 18 & 2,62 & 0,291 & 1,95 & 4,49 & 7,10 \\
\hline Qualea multiflora Mart. & 24 & 2,54 & 20 & 2,91 & 0,231 & 1,55 & 4,09 & 7,00 \\
\hline Astronium fraxinifolium Schott. & 20 & 2,12 & 17 & 2,47 & 0,328 & 2,20 & 4,31 & 6,78 \\
\hline Guapira graciliflora (Mart. ex Schmidt) Lund & 29 & 3,07 & 10 & 1,45 & 0,309 & 2,07 & 5,14 & 6,59 \\
\hline Pseudobombax longiflorum (Mart. \& Zucc.) A. Robyns & 18 & 1,90 & 15 & 2,18 & 0,222 & 1,49 & 3,39 & 5,57 \\
\hline Strychnos pseudoquina A. St.-Hil. & 11 & 1,16 & 10 & 1,45 & 0,400 & 2,68 & 3,84 & 5,29 \\
\hline Byrsonima coccolobifolia H.B. \& K. & 17 & 1,80 & 13 & 1,89 & 0,227 & 1,52 & 3,32 & 5,21 \\
\hline Kielmeyera speciosa A. St.-Hil. & 16 & 1,69 & 15 & 2,18 & 0,193 & 1,29 & 2,98 & 5,17 \\
\hline Terminalia argentea Mart. \& Zucc. & 11 & 1,16 & 10 & 1,45 & 0,341 & 2,28 & 3,45 & 4,90 \\
\hline Bowdichia virgilioides H.B. \& K. & 11 & 1,16 & 10 & 1,45 & 0,313 & 2,09 & 3,26 & 4,71 \\
\hline Erythroxylum suberosum A. St.-Hil. & 17 & 1,80 & 12 & 1,74 & 0,157 & 1,06 & 2,85 & 4,60 \\
\hline Licania humilis Cham. ex Schlecht. & 10 & 1,06 & 9 & 1,31 & 0,325 & 2,18 & 3,24 & 4,55 \\
\hline Machaerium acutifolium Vog. & 14 & 1,48 & 12 & 1,74 & 0,167 & 1,12 & 2,60 & 4,35 \\
\hline Eugenia aurata Berg & 13 & 1,38 & 13 & 1,89 & 0,121 & 0,81 & 2,19 & 4,08 \\
\hline Salvertia convallariaeodora A. St.-Hil. & 12 & 1,27 & 12 & 1,74 & 0,154 & 1,03 & 2,30 & 4,05 \\
\hline Eriotheca gracilipes (K. Schum.) A. Robyns & 9 & 0,95 & 9 & 1,31 & 0,241 & 1,62 & 2,57 & 3,88 \\
\hline Guapira noxia (Netto) Lund & 12 & 1,27 & 9 & 1,31 & 0,170 & 1,14 & 2,41 & 3,72 \\
\hline Lafoensia pacari A. St.-Hil. & 12 & 1,27 & 10 & 1,45 & 0,133 & 0,89 & 2,16 & 3,62 \\
\hline Hymenaea stigonocarpa Mart. ex Hayne & 11 & 1,16 & 9 & 1,31 & 0,138 & 0,92 & 2,09 & 3,40 \\
\hline Ouratea spectabilis (Mart.) Engl. & 8 & 0,85 & 7 & 1,02 & 0,180 & 1,21 & 2,06 & 3,07 \\
\hline Buchenavia tomentosa Eichl. & 4 & 0,42 & 4 & 0,58 & 0,302 & 2,03 & 2,45 & 3,03 \\
\hline Caryocar brasiliense Camb. & 6 & 0,63 & 6 & 0,87 & 0,218 & 1,46 & 2,10 & 2,97 \\
\hline Tabebuia ochracea (Cham.) Standl. & 7 & 0,74 & 7 & 1,02 & 0,177 & 1,19 & 1,93 & 2,94 \\
\hline Couepia grandiflora (Mart. \& Zucc.) Benth. \& Hook. f. & 10 & 1,06 & 8 & 1,16 & 0,097 & 0,65 & 1,71 & 2,88 \\
\hline Dimorphandra mollis Benth. & 8 & 0,85 & 8 & 1,16 & 0,115 & 0,77 & 1,62 & 2,78 \\
\hline Mouriri elliptica Mart. & 10 & 1,06 & 6 & 0,87 & 0,120 & 0,80 & 1,86 & 2,73 \\
\hline Syagrus comosa (Mart.) Becc. & 9 & 0,95 & 8 & 1,16 & 0,077 & 0,52 & 1,47 & 2,63 \\
\hline Curatella americana $\mathrm{L}$. & 6 & 0,63 & 6 & 0,87 & 0,128 & 0,86 & 1,50 & 2,37 \\
\hline Dalbergia miscolobium Benth. & 5 & 0,53 & 5 & 0,73 & 0,148 & 0,99 & 1,52 & 2,25 \\
\hline Anacardium occidentale $\mathrm{L}$. & 6 & 0,63 & 6 & 0,87 & 0,099 & 0,66 & 1,30 & 2,17 \\
\hline Annona coriacea Mart. & 6 & 0,63 & 5 & 0,73 & 0,116 & 0,78 & 1,42 & 2,14 \\
\hline Erythroxylum tortuosum Mart. & 7 & 0,74 & 7 & 1,02 & 0,051 & 0,34 & 1,08 & 2,10 \\
\hline Connarus suberosus Planch. & 7 & 0,74 & 7 & 1,02 & 0,050 & 0,33 & 1,08 & 2,09 \\
\hline Emmotum nitens (Benth.) Miers. & 7 & 0,74 & 6 & 0,87 & 0,063 & 0,42 & 1,16 & 2,04 \\
\hline Vatairea macrocarpa (Benth.) Ducke & 6 & 0,63 & 6 & 0,87 & 0,065 & 0,44 & 1,07 & 1,95 \\
\hline Salacia crassifolia (Mart.) G. Don. & 5 & 0,53 & 5 & 0,73 & 0,089 & 0,60 & 1,13 & 1,86 \\
\hline Mezilaurus crassiramea (Meissn.) Taub. & 5 & 0,53 & 5 & 0,73 & 0,083 & 0,56 & 1,09 & 1,81 \\
\hline Peltogyne confertiflora (Hayne) Benth. & 5 & 0,53 & 5 & 0,73 & 0,077 & 0,52 & 1,05 & 1,78 \\
\hline Tabebuia aurea (Manso) Benth. \& Hook. f. ex S. Moore & 4 & 0,42 & 4 & 0,58 & 0,097 & 0,65 & 1,07 & 1,66 \\
\hline Pouteria ramiflora (Mart.) Radlk. & 3 & 0,32 & 3 & 0,44 & 0,134 & 0,90 & 1,21 & 1,65 \\
\hline Mimosa laticifera Rizzini \& Mattos & 4 & 0,42 & 4 & 0,58 & 0,038 & 0,26 & 0,68 & 1,26 \\
\hline Luetzelburgia praecox (Harms.) Harms. & 3 & 0,32 & 3 & 0,44 & 0,051 & 0,34 & 0,66 & 1,09 \\
\hline Acosmium dasycarpum (Vog.) Yakovlev. & 3 & 0,32 & 3 & 0,44 & 0,045 & 0,31 & 0,62 & 1,06 \\
\hline
\end{tabular}


Tabela 3 (continuação)

\begin{tabular}{|c|c|c|c|c|c|c|c|c|}
\hline Espécies & $\mathrm{Ni}$ & DR & FA & FR & DoA & DoR & IVC & IVI \\
\hline Sclerolobium aureum (Tul.) Benth. & 3 & 0,32 & 3 & 0,44 & 0,033 & 0,22 & 0,54 & 0,98 \\
\hline Callisthene fasciculata Mart. & 3 & 0,32 & 3 & 0,44 & 0,031 & 0,21 & 0,53 & 0,97 \\
\hline Rourea induta Planch. & 3 & 0,32 & 3 & 0,44 & 0,017 & 0,12 & 0,43 & 0,87 \\
\hline Xylopia aromatica (Lam.) Mart. & 2 & 0,21 & 2 & 0,29 & 0,052 & 0,35 & 0,56 & 0,85 \\
\hline Myrcia camapuanensis N.F.E. Silveira & 3 & 0,32 & 2 & 0,29 & 0,024 & 0,16 & 0,48 & 0,77 \\
\hline Aspidosperma multiflorum A. DC. & 2 & 0,21 & 2 & 0,29 & 0,031 & 0,21 & 0,42 & 0,71 \\
\hline Dipteryx alata Vog. & 2 & 0,21 & 2 & 0,29 & 0,025 & 0,17 & 0,38 & 0,67 \\
\hline Casearia sylvestris $\mathrm{Sw}$. & 2 & 0,21 & 2 & 0,29 & 0,017 & 0,11 & 0,33 & 0,62 \\
\hline Simarouba versicolor A. St.-Hil. & 2 & 0,21 & 2 & 0,29 & 0,017 & 0,11 & 0,33 & 0,62 \\
\hline Vernonia ferruginea Less. & 2 & 0,21 & 2 & 0,29 & 0,013 & 0,09 & 0,30 & 0,59 \\
\hline Himatanthus obovatus (M. Arg.) R.E. Woodson & 2 & 0,21 & 2 & 0,29 & 0,010 & 0,07 & 0,28 & 0,57 \\
\hline Pterodon pubescens (Benth.) Benth. & 1 & 0,11 & 1 & 0,15 & 0,046 & 0,31 & 0,42 & 0,56 \\
\hline Antonia ovata Pohl & 2 & 0,21 & 2 & 0,29 & 0,008 & 0,05 & 0,27 & 0,56 \\
\hline Heisteria ovata Benth. & 1 & 0,11 & 1 & 0,15 & 0,045 & 0,30 & 0,41 & 0,56 \\
\hline Myrcia sellowiana Berg & 2 & 0,21 & 1 & 0,15 & 0,008 & 0,06 & 0,27 & 0,42 \\
\hline Styrax camporum Pohl & 1 & 0,11 & 1 & 0,15 & 0,017 & 0,12 & 0,22 & 0,37 \\
\hline Austroplenckia populnea Reiss. & 1 & 0,11 & 1 & 0,15 & 0,015 & 0,11 & 0,21 & 0,36 \\
\hline Andira cuiabensis Benth. & 1 & 0,11 & 1 & 0,15 & 0,013 & 0,09 & 0,19 & 0,34 \\
\hline Myrtaceae-NI & 1 & 0,11 & 1 & 0,15 & 0,011 & 0,08 & 0,19 & 0,33 \\
\hline Tocoyena formosa (Cham. \& Schlecht.) K. Schum. & 1 & 0,11 & 1 & 0,15 & 0,009 & 0,06 & 0,17 & 0,31 \\
\hline Palicourea rigida Kunth & 1 & 0,11 & 1 & 0,15 & 0,005 & 0,04 & 0,14 & 0,29 \\
\hline \multirow[t]{2}{*}{ Brosimum gaudichaudii Tréc. } & 1 & 0,11 & 1 & 0,15 & 0,005 & 0,04 & 0,14 & 0,29 \\
\hline & 945 & 100 & 688 & 100 & 14,945 & 100 & 200 & 300 \\
\hline
\end{tabular}

entre as duas comunidades e apontam para uma dominância mais marcante de $H$. glandulosa no cerradão do que $Q$. parviflora no cerrado sensu stricto . O índice de similaridade de Sørensen $(0,58)$ e Morisita $(0,21)$ indicam baixa similaridade florística, reforçando as diferenças também nesse aspecto. Os valores de similaridade ficaram dentro de uma faixa de variação encontrada por diversos autores (Costa \& Araújo 2001; Ribeiro et al. 1985; Felfili et al. 1993).

No cerradão foram encontrados 942 indivíduos pertencentes a 77 espécies, 65 gêneros e 36 famílias botânicas. Os indivíduos mortos (em pé) perfizeram

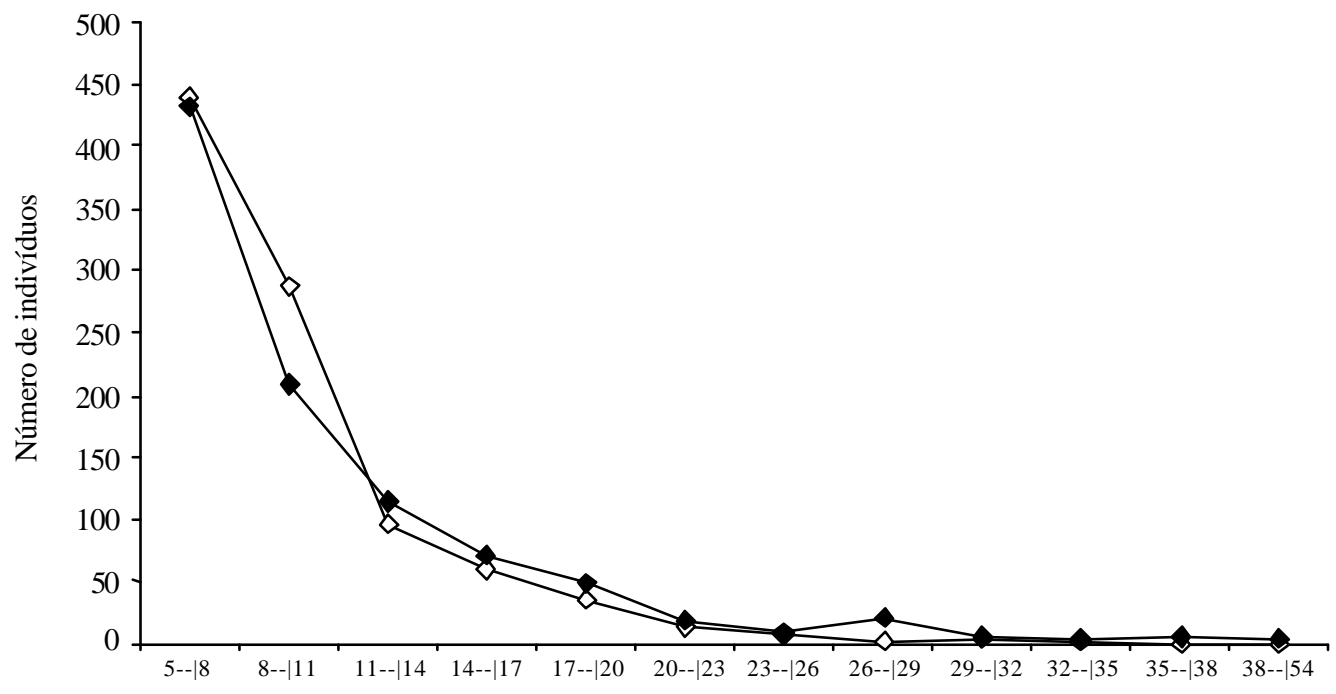

Classes de diâmetro $(\mathrm{cm})$

Figura 5. Distribuição de diâmetros de árvores em um cerrado sensu stricto e um cerradão na Reserva Mário Viana, Nova Xavantina, MT, Brasil. $-\diamond-$ Cerrado sensu stricto; $-\diamond-=$ Cerrado. 
$8,5 \%$ da densidade total. Vinte e três espécies apresentaram apenas um ou dois indivíduos, representando cerca de $30 \%$ do total de espécies e cerca de $4 \%$ do total de indivíduos. As espécies de maior frequiência foram $H$. glandulosa e Xylopia aromatica, que ocorreram em $82 \%$ e $76 \%$ das parcelas, respectivamente, sendo que dez espécies ocorreram em apenas uma parcela. No cerrado sensu stricto foram amostrados 945 indivíduos pertencentes a 77 espécies, 68 gêneros e 38 famílias. Os indivíduos mortos (em pé) perfizeram $11 \%$ da densidade total. As espécies raras, com apenas um ou dois indivíduos, representaram $23 \%$ do total de espécies e $3 \%$ da densidade total. Q. parviflora e Davilla elliptica foram as espécies mais freqüentes, ocorrendo em $80 \%$ das parcelas, sendo que 10 espécies ocorreram em apenas uma parcela. $\mathrm{O}$ índice de diversidade de espécies de Shannon (H') e a equabilidade de Pielou (J) para o cerrado sensu stricto (Tab. 1) foram, respectivamente, 3,78 e 0,870 . Para o cerradão, os mesmo índices foram 3,67 e 0,846.

De acordo com Ratter et al. (1977), a estrutura fitossociológica de um cerradão pode variar em função do tipo de solo. Os autores mencionaram que cerradão sobre solo mesotrófico é caracterizado por Magonia pubescens, Luehea paniculata, Physocalymma scaberrimum e Callisthene fasciculata, entre outras, enquanto o cerradão indiferenciado apresenta Qualea grandiflora e Vochysia tucanorum como espécies principais. Já no caso do cerradão sobre solos distróficos, as principais espécies em IVI são Hirtella glandulosa, Emmotum nitens, Sclerolobium paniculatum e Vochysia haenkeana. Ribeiro \& Haridasan (1984) encontraram Emmotum nitens, Ocotea spixiana e Sclerolobium paniculatum var. rubiginosum como as espécies mais importantes em um cerradão sobre solos distróficos no Distrito Federal. No presente estudo, somente $V$. haenkeana não estava entre as de maior IVI.

Solos - O solo sob ambas fitofisionomias apresentouse distrófico $\left(\mathrm{Ca}<0,4 \mathrm{cmol}_{\mathrm{c}} \mathrm{kg}^{-1}\right.$ ), álico ( $\mathrm{Al}>$ $1,3 \mathrm{cmol}_{\mathrm{c}} \mathrm{kg}^{-1}$ ) e ácido $(\mathrm{pH}<5,0)$ ao longo do perfil (Fig. 7, 8). Os resultados de análises dos dois perfis do solo foram confirmados pelas análises das 25 amostras superficiais (Fig. 9, 10). O Al trocável mostrou-se um pouco mais alto ao longo do perfil no cerradão, com valor máximo de aproximadamente $2,6 \mathrm{cmol}_{\mathrm{c}} \mathrm{kg}^{-1}$ contra $1,4 \mathrm{cmol}_{\mathrm{c}} \mathrm{kg}^{-1}$ no perfil do cerrado sensu stricto. Em relação aos teores de cálcio e magnésio no perfil do solo, as diferenças entre as áreas não foram significativas, sendo inferiores a $0,02 \mathrm{cmol}_{\mathrm{c}} \mathrm{kg}^{-1} \mathrm{e}$ $0,102 \mathrm{cmol}_{\mathrm{c}} \mathrm{kg}^{-1}$ (Fig. 7), respectivamente, além do $\mathrm{pH}$, que apresentou pequenas diferenças em água $(<0,3)$ e em $\mathrm{KCl}(<0,14)$.

Os teores de macronutrientes, alumínio, os percentuais de matéria orgânica, carbono e nitrogênio, bem como os valores de $\mathrm{pH}$ em água e em $\mathrm{KCl}$ encontrados no solo sob as duas comunidades estudadas apresentaram-se muito próximos aos encontrados em vários outros solos distróficos para vegetação de cerrado sensu stricto e cerradão em diferentes regiões

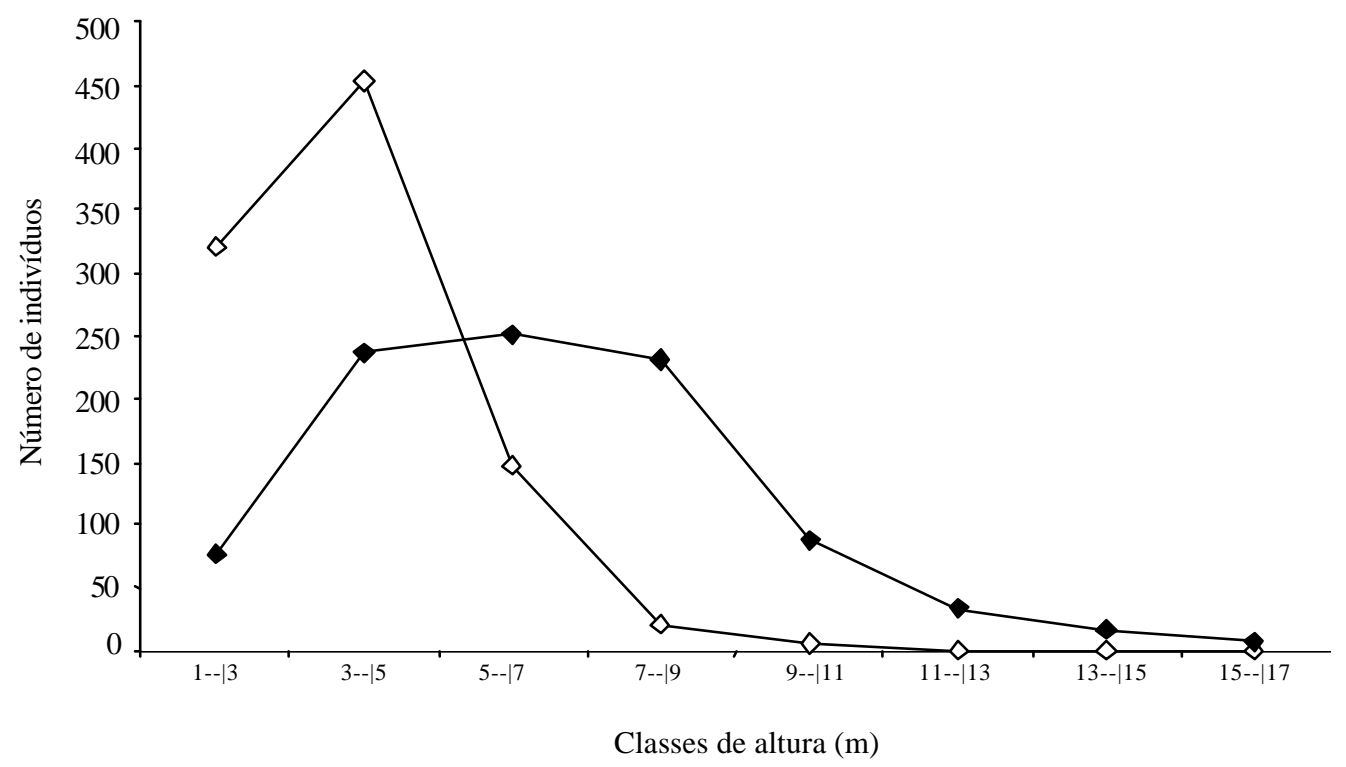

Figura 6. Distribuição de alturas de árvores em um cerrado sensu stricto e um cerradão na Reserva Mário Viana, Nova Xavantina, MT, Brasil. $-\diamond-$ Cerrado sensu stricto; $-\nabla-=$ Cerrado. 
do Bioma Cerrado (J.F. Ribeiro, dados não publicados; Ribeiro \& Haridasan 1984; Haridasan 1987; Furley \& Ratter 1988; Furley et al. 1988; Haridasan 1992; Sassaki et al. 1999; Haridasan 2000; Costa \& Araújo 2001; Ruggiero et al. 2002).

Como os valores dos macronutrientes, alumínio e pH do solo não diferiram entre as áreas, tanto nos perfis quanto nas amostras superficiais, o presente estudo obteve resultados distintos daqueles verificados por
Alvim \& Araújo (1952), Goodland (1971b), Goodland \& Pollard (1973) e Lopes \& Cox (1977) em outras localidades do Bioma Cerrado, onde os autores concluíram por uma maior fertilidade nos solos sob cerradão. Nossos resultados assemelham-se mais aos de Askew et al. (1971), Gibbs et al. (1983), J.F. Ribeiro (dados não publicados) e Haridasan (1992), que não verificaram diferenças de fertilidade nos solos sob cerradão e cerrado sensu stricto .

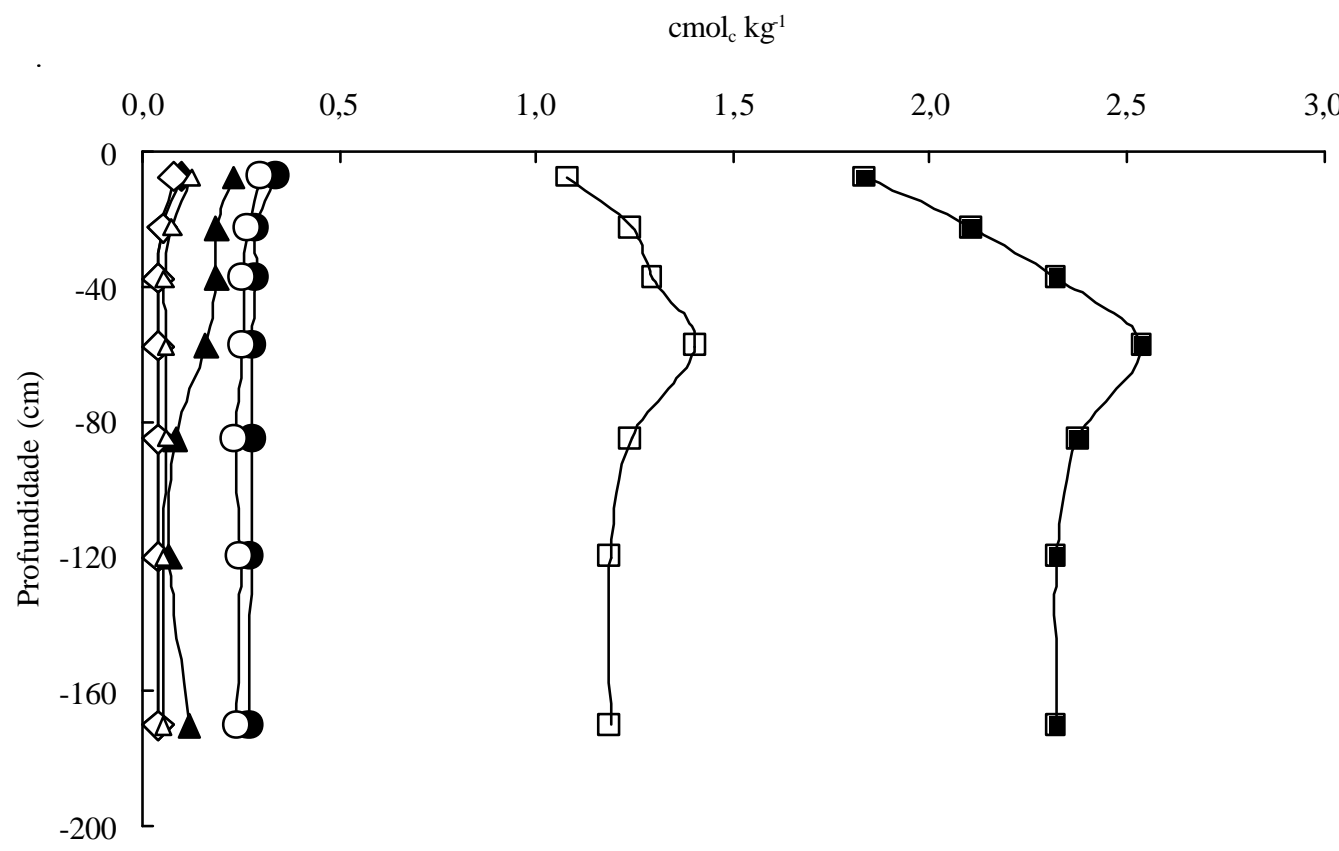

Figura 7. Cátions trocáveis no solo sob o cerradão e o cerrado sensu stricto na Reserva Mário Viana, Nova Xavantina, MT, Brasil.

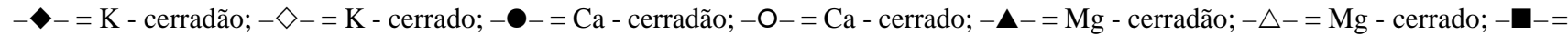
$\mathrm{Al}$ cerradão; $\square=\mathrm{Al}$ - cerrado.

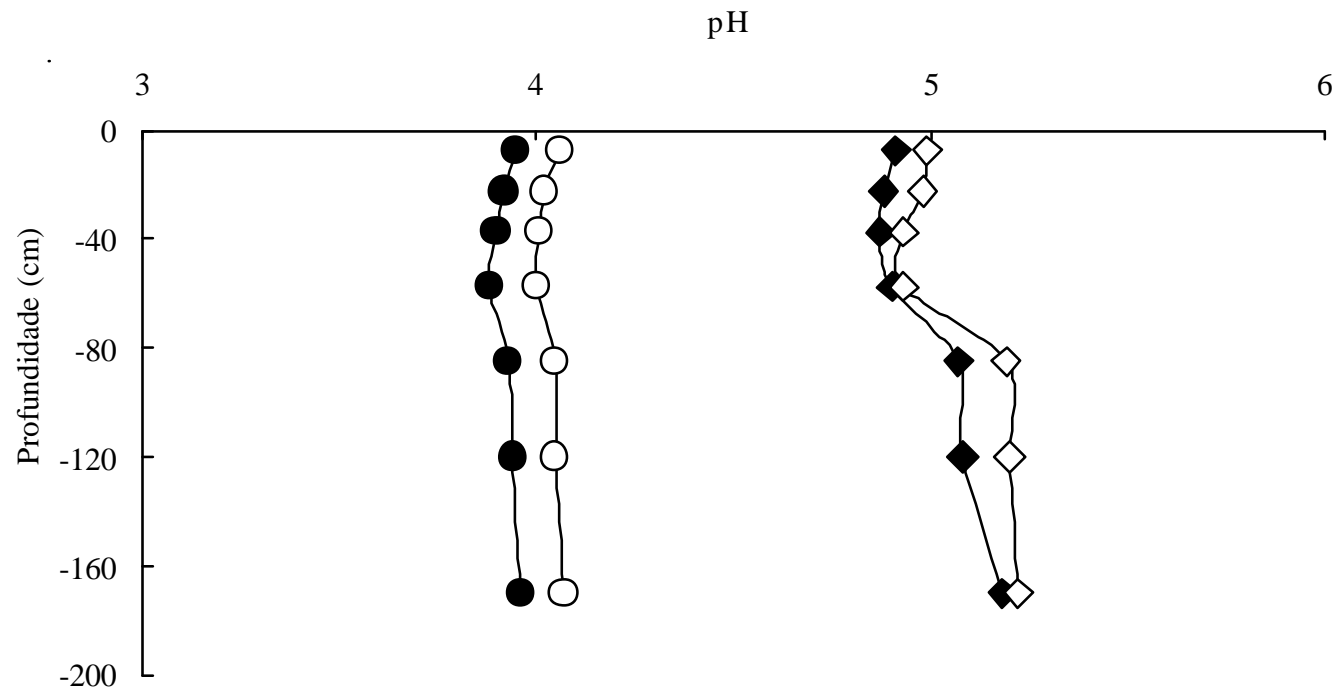

Figura 8. pH no solo sob o cerradão e o cerrado sensu stricto na Reserva Mário Viana, Nova Xavantina, MT, Brasil. $-\bullet-=$ pH em água - cerradão; - - - = pH em KCl - cerradão; $-\triangle-=$ pH em água cerrado; $-\mathrm{O}-=$ pH em $\mathrm{KCl}$ - cerrado. 
Como o cerradão apresenta maior biomassa que o cerrado sensu stricto, a quantidade maior de nutrientes requerida para a sua manutenção pode ter existido no solo no passado, mantendo-se até o presente através da ciclagem de nutrientes (Haridasan 1987; 199; 2000). Desta forma, não obstante outros fatores, como presença de fogo, diferenças genéticas e/ou possíveis diferenças no regime hídrico do solo em função de sua textura, é provável que o cerradão do presente estudo permaneça confinado em seu sítio atual por não existir quantidade suficiente de nutrientes nas áreas adjacentes
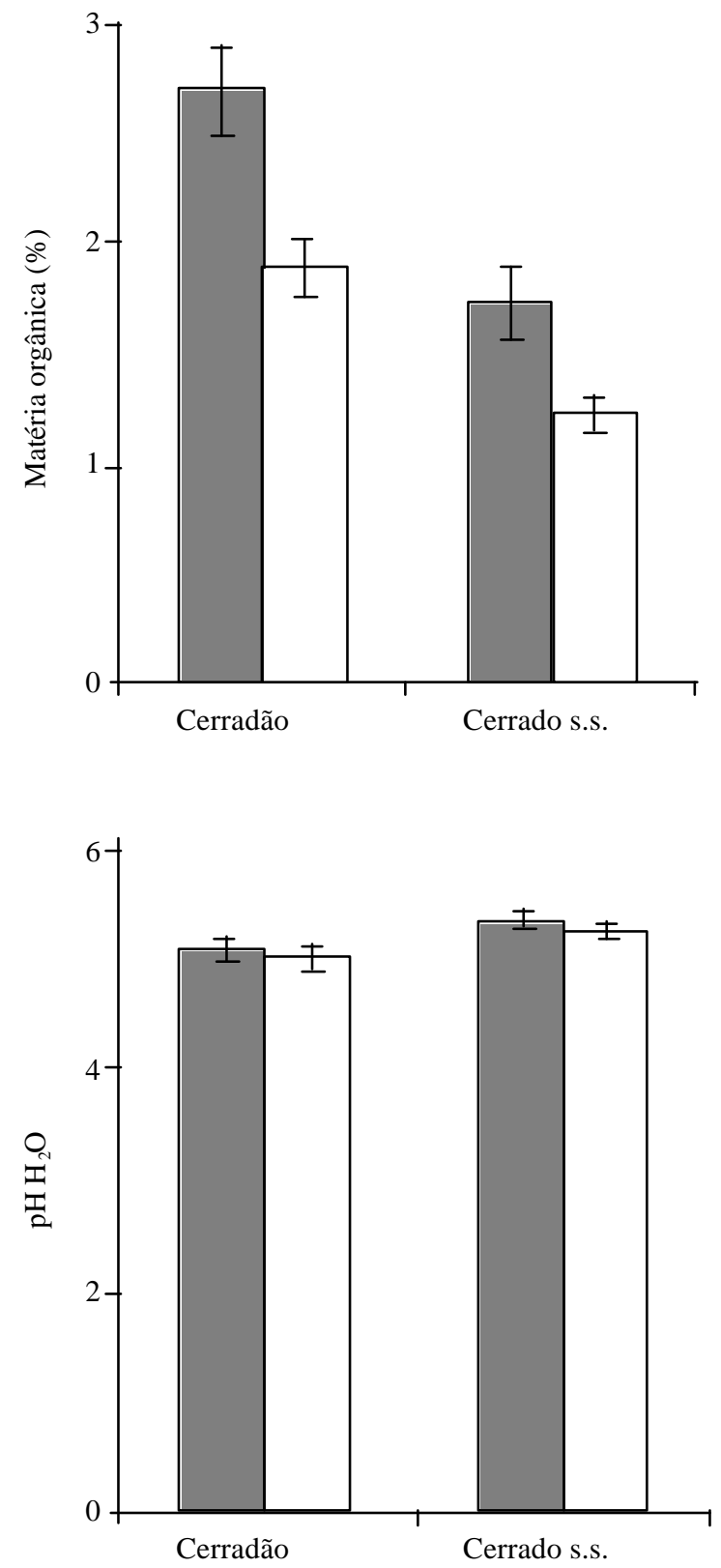

para que esta vegetação possa sobstituir o cerrado sensu stricto.

Originalmente, o cerrado sensu stricto era a vegetação predominante na paisagem da região leste de Mato Grosso e o cerradão ocorria apenas em manchas esparsas e geralmente nas áreas próximas do contato entre cerrado e floresta de transição préamazônica. O solo sob estas manchas de cerradão pode ter sido originado, pelo menos em parte, de rochas calcáreas, cujos afloramentos são muito comuns na região. Esta poderia ter sido a origem de sítios um
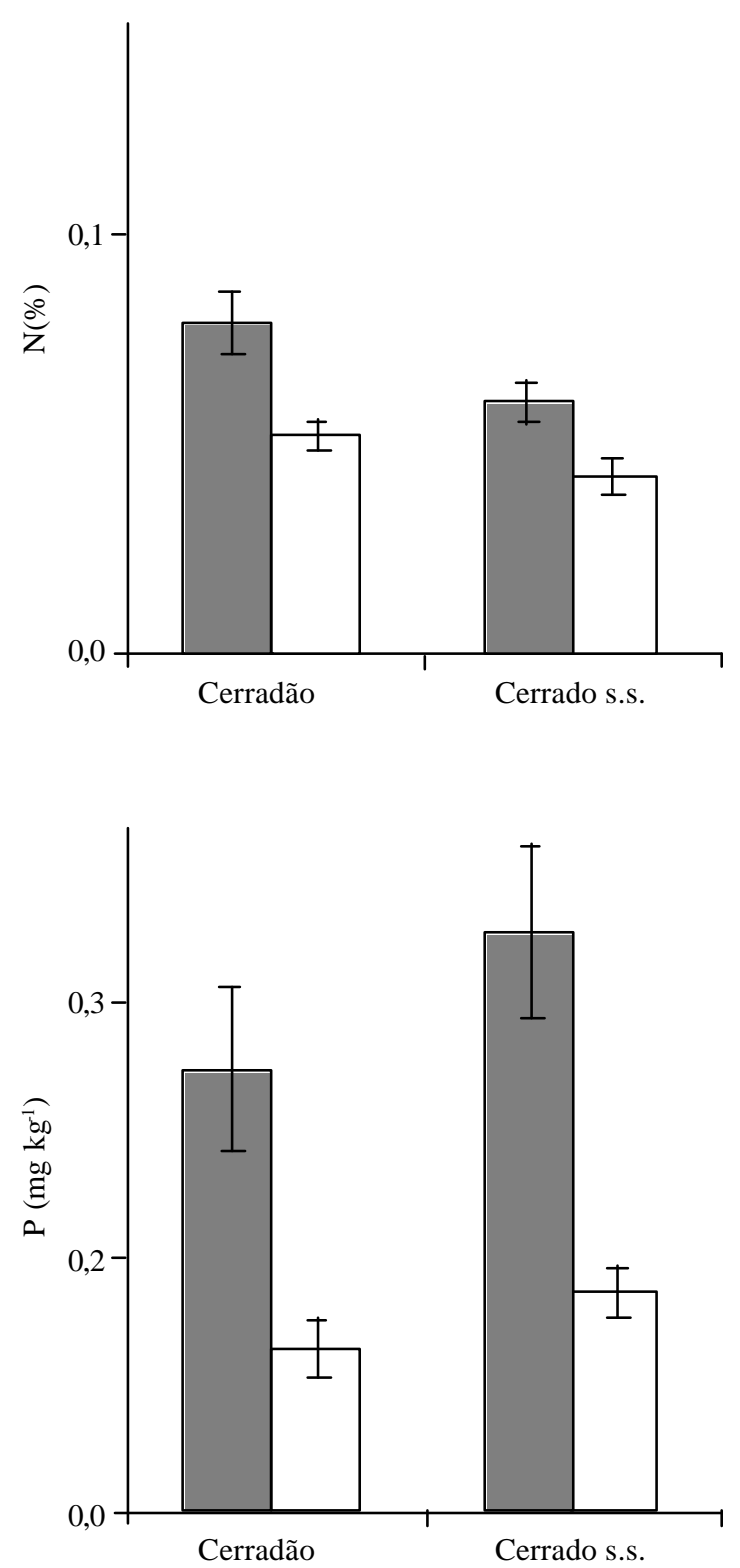

Figura 9. Características das camadas superficiais do solo sob o cerrado sensu stricto e o cerradão na Reserva Mário Viana, Nova Xavantina, MT, Brasil. As barras representam o desvio padrão da média (25 amostras). $\square=0 \mathrm{a} 10 \mathrm{~cm} ; \square=10 \mathrm{a} 20 \mathrm{~cm}$. 
pouco mais ricos em nutrientes, o suficiente para permitir o estabelecimento dos cerradões em detrimento do cerrado sensu stricto no passado.

Entre as duas fitofisionomias, as variações relevantes foram relativas à composição granulométrica dos solos. O solo sob o cerradão apresentou-se consideravelmente mais argiloso ao longo de todo o perfil. Entre 0-20 cm de profundidade, o teor de argila foi de aproximadamente $28 \%$, aumentando para mais de $40 \%$ entre $45-200 \mathrm{~cm}$, contra $18 \%$ entre $0-20 \mathrm{~cm}$ e
$28 \%$ entre 45 e $200 \mathrm{~cm}$ no cerrado sensu stricto (Fig. 11).

Como a textura foi o único fator edáfico que apresentou diferenças entre as áreas, sugerimos que sejam conduzidos estudos para a verificação do comportamento da água em ambos os solos e as relações hídricas das principais espécies arbóreas. Além disso, seria importante a investigação sobre o material de origem dos solos nessas fitofisionomias, o que poderia indicar a história geológica de ambos e o
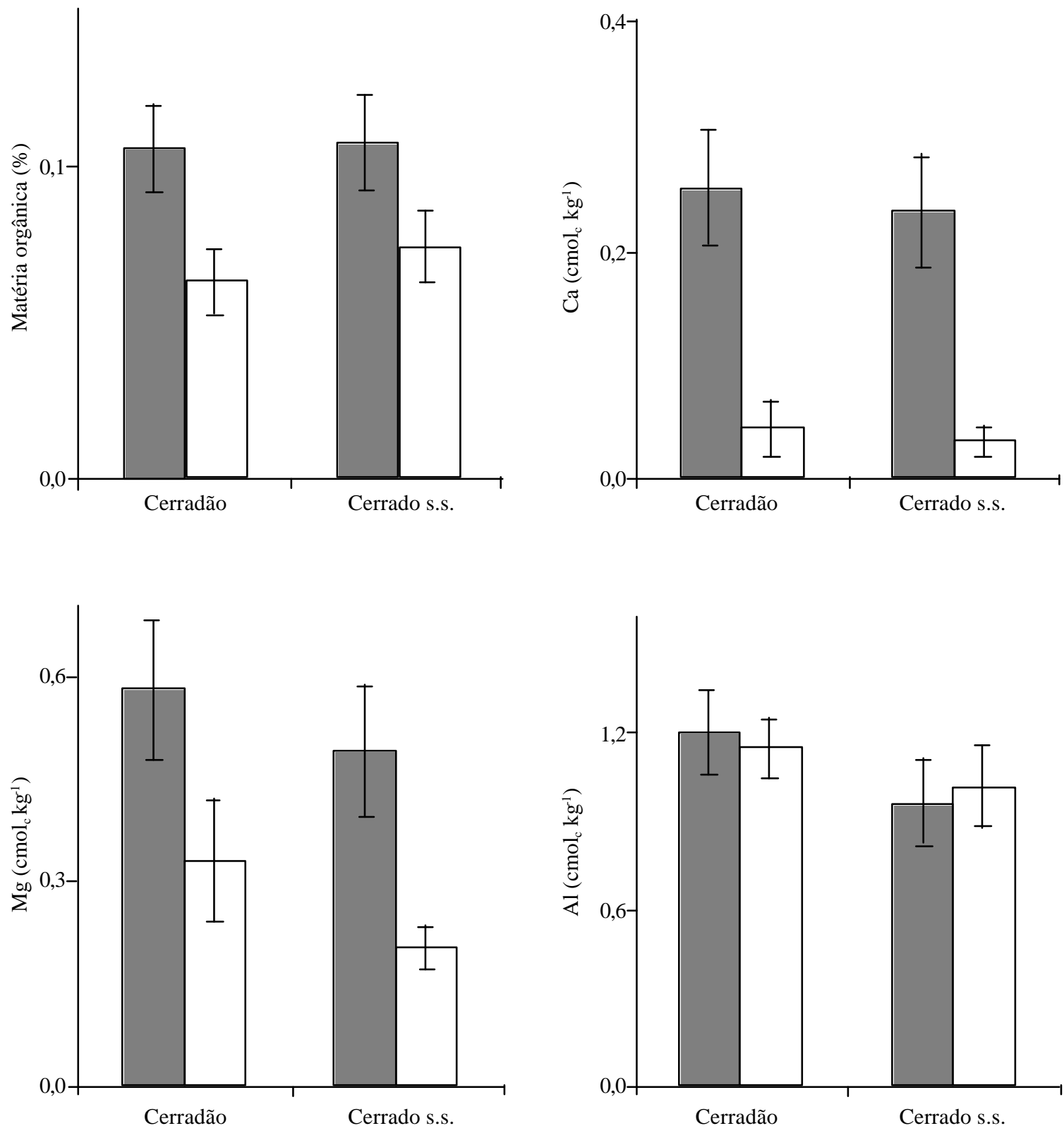

Figura 10. Cátions trocáveis nas camadas superficiais do solo sob o cerrado sensu stricto e o cerradão na Reserva Mário Viana, Nova Xavantina, MT, Brasil. As barras representam o desvio padrão da média (25 amostras). $\square=0$ a $10 \mathrm{~cm} ; \square=10 \mathrm{a} 20 \mathrm{~cm}$. 


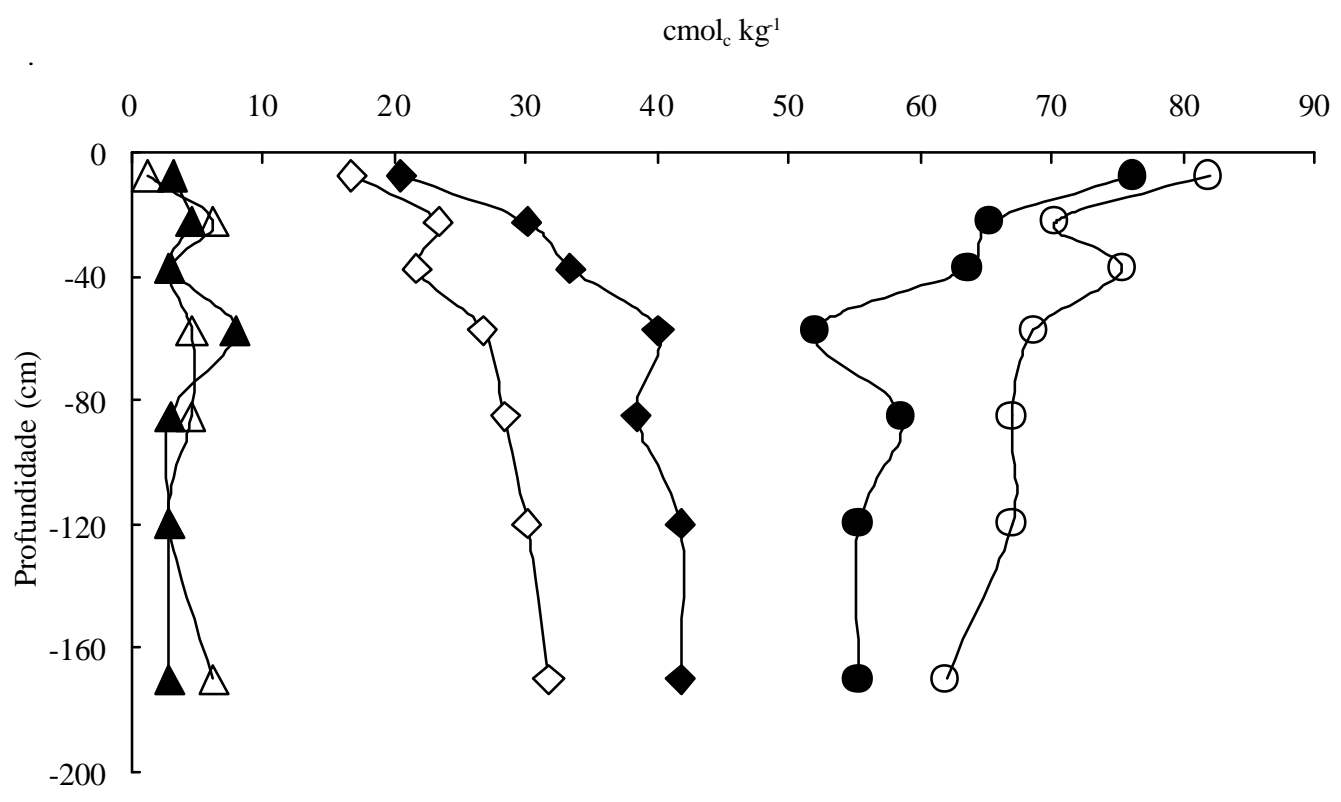

Figura 11. Textura do solo sob o cerradão e o cerrado sensu stricto na Reserva Mário Viana, Nova Xavantina, MT, Brasil. $-\bullet-=$ Argila - cerradão; $-\diamond_{-}=$Argila - cerrado $;-\bullet-=$ Areia - cerradão $;-O-=$ Areia - cerrado $;-\mathbf{\Delta}-=$ Silte - cerradão; $-\triangle-=$ Silte - cerrado.

papel desta no fornecimento diferencial de nutrientes no passado.

Conclui-se que a hipótese de que o solo sob cerradão seria mais fértil, com menores teores de alumínio trocável, não foi confirmada. Uma das explicações plausíveis em relação à existência das duas fitofisionomias está associada à composição granulométrica dos solos. Presume-se que o solo sob cerradão, mais argiloso, tem maior capacidade de retenção de água disponível. Portanto, é capaz de suprir mais adequadamente as plantas com água nos processos de síntese de biomassa, bem como possui maior fertilidade ativa, pois a disponibilidade de água regula a dinâmica dos nutrientes no solo e sua absorção pelas plantas.

\section{Referências bibliográficas}

Allen, S.E. 1974. Chemical analysis of ecological materials . Oxford, Blackwell Scientific Publications.

Alvin, P.T. \& Araújo, W.A. 1952. El suelo como factor ecológico en el desarrollo de la vegetación en el centrooeste del Brasil. Turrialba 2(4): 153-160.

Araújo, G.M. \& Haridasan, M. 1988. A comparison of the nutrients status of two forests on dystrophic and mesotrophic soils in the cerrado region of central Brazil. Communications in Soil Science and plant analysis 19: 1075-1089.

Askew, K.P.; Montgomery, R.F. \& Searl, P.L. 1971. Soil and soil moisture as factors influencing the distribution of the vegetation formations of the Serra do Roncador, Mato Grosso. Pp.150-160. In: M.G. Ferri (ed.). III Simpósio sobre o Cerrado). São Paulo, Edgard Blücher.
Camargo, A.P. 1963. Clima do cerrado. Pp.75-59. In: M.G. Ferri (coord.). Simpósio sobre o Cerrado. São Paulo, EDUSP.

Costa, A.A. \& Araújo, G.M. 2001. Comparação da vegetação arbórea de cerradão e cerrado na Reserva do Panga, Uberlândia, Minas Gerais. Acta Botanica Brasilica 15(1): 63-72.

Eiten, G. 1972. The cerrado vegetation of Brazil. The Botanical Review 38(2): 201-338.

Eiten, G. 1994. Vegetação do Cerrado. Pp. 17-75. In: M.N. Pinto (org.). Cerrado: caracterização, ocupação e perspectivas. Brasília, Editora da UnB.

Felfili, J.M. \& Silva-Júnior, M.C. 1988. Distribuição dos diâmetros numa faixa de cerrado na Fazenda Água Limpa (FAL) em Brasília-DF. Acta Botanica Brasilica 2 : 85-104.

Felfili, J.M.; Silva-Júnior, M.C.; Rezende, A.V.; Machado, J.W.B.; Walter, B.M.T.; Nogueira, P.E. \& Hay, J.D. 1993. Análise comparativa da florística e fitossociologia da vegetação arbórea do cerrado sensu stricto na Chapada pratinha, DF-Brasil. Acta Botanica Brasilica 6: 27-46.

Felfili, J.M. 1997. Diameter and height distributions in a gallery forest tree community and some of its main species in central Brazil over a six-year period (1985-1991). Revista Brasileira de Botânica 20: 155-162.

Felfili, J.M.; Nogueira, P.E.; Silva-Júnior, M.C.; Marimon, B.S. \& Delitti, W.B.C. 2002. Composição florística e fitossociologia do cerrado sentido restrito no município de Água Boa-MT. Acta Botanica Brasilica 16(1): 103-112.

Furley, P.A.; Ratter, J.A. \& Gifford, D.R. 1988. Observations on the vegetation of esatern Mato Grosso, Brazil III. The woody vegetation and soils of the Morro da Fumaça, Torixoréu. Phil. Trans. R. Soc. Lond. B 235: 259-280.

Furley, P.A \& Ratter, J.A. 1988. Soil resources and plant communities of the central brazilian cerrado and their development. Journal of Biogeography 15: 97-108. 
Gibbs, P.E.; Leitão-Filho, H.F. \& Shepherd, G. 1983. Floristic composition and community structure in an area of cerrado in SE Brazil. Flora 173: 433-449.

Goodland, R. 1971a. The cerrado oxisols of the Triângulo Mineiro, central Brazil. Anais da Academia Brasileira de Ciências 43: 407-414.

Goodland, R. 1971b. A physiognomic analysis of the cerrado vegetation of central Brazil. Journal of Ecology 59:411-419.

Goodland, R. \& Pollard, R. 1973. The Brazilian cerrado vegetation: a fertility gradient. Journal of Ecology 61:219224.

Haridasan, M. 1987. Distribution and mineral nutrition of aluminium-accumulating species in different plant communities of the cerrado region of the central Brazil. Pp. 309-348. In: J.J. San Jose \& R. Montes (eds.). La Capacidad Bioreprodutiva de Sabanas. IVIC, Caracas, Venezuela.

Haridasan, M. 1992. Observations on soils, foliar nutrient concentration and floristic composition of cerradosensu stricto and cerradão communities in central Brazil. Pp.171-184. In: P.A. Furley; J. Proctor \& J.A. Ratter (eds.). Nature and Dynamics of Forest-Savanna Boundaries. London, Chapman \& Hall Publishing.

Haridasan, M. 2000. Nutrição mineral das plantas nativas do Cerrado. Revista Brasileira de Fisiologia Vegetal 12(1): 54-64.

Horn, H.S. 1966. Measurement of "overlap" in comparative ecological studies. The American Naturalist 100: 419-424.

Lopes, A.S. \& Cox, F.R. 1977. Cerrado vegetation in Brazil: an edaphic gradient. Agronomy Journal 69: 828-831.

Marimon, B.S.; Varella, R.F. \& Marimon-Júnior, B.H. 1998. Fitossociologia de uma área de cerrado de encosta em Nova Xavantina, Mato Grosso. Boletim do Herbário Ezechias Paulo Heringer 3: 82-101.

Nascimento, M.T. \& Saddi, N. 1992. Structure and floristic composition in an area of cerrado in Cuiabá-MT, Brazil. Revista Brasileira de Botânica 15: 47-55.

Nimer, E. 1989. Climatologia do Brasil. Rio de Janeiro, Instituto Brasileiro de Geografia e Estatística.
Oliveira-Filho, A.T.; Shepherd, G.J.; Martins, F.R. \& Stubblebine, W.H. 1990. Environmental factors affecting physiognomic and floristic variation in an area of cerrado in central Brazil. Journal of Tropical Ecology 5: 413-451.

RADAMBRASIL. 1981. Levantamento de recursos naturais. Rio de Janeiro, Ministério das Minas e Energia 25, folha SD22/Goiás.

Ratter, J.A. 1971. Some notes on two types of cerradão occuring in northeastern Mato Grosso. Pp.110-112. In: M.G. Ferri (ed.). III Simpósio Sobre o Cerrado. São Paulo, EDUSP/ EdgardBlücher.

Ratter, J.A.; Richards, P.W.; Argent, G. \& Gifford, D.R. 1973. Observations on the vegetationof the northeastern Mato Grosso I. The woody vegetation types of the XavantinaCachimbo Expedition area. Phil. Trans. R. Soc. Lond. B 266:449-492.

Ratter, J.A.; Askew, G.P.; Montgomery, R.F. \& Gifford, D.R. 1977. Observações adicionais sobre o cerradão de solos mesotróficos no Brasil central. Pp.303-316. In: M.G. Ferri (ed.). IV Simpósio sobre o Cerrado: Bases para a Utilização Agropecuária. São Paulo, EDUSP.

Ribeiro, J.F. \& Haridasan, M. 1984. Comparação fitossociológica de um cerrado denso e um cerradão em solos distróficos no Distrito Federal. In: Anais do ${ }^{\circ}{ }^{\circ}$ Congresso Nacional de Botânica.SBB, Manaus.

Ribeiro, J.F.; Silva, J.C.S. \& Batmanian, G.J. 1985. Fitossociologia de tipos fisionômicos de cerrado em planaltina-DF. Revista Brasileira de Botânica 8: 131-142.

Ruggiero, P.G.C.; Batalha, M.A.; Pivelo, V.R. \& Meireles, S.T. 2002. Soil-vegetation relationships in cerrado (Brazilian savanna) and semideciduous forest, Southeastern Brazil.Plant Ecology 160: 1-16.

Sassaki, R.M.; Rondon, J.N.; Zaidan, L.B.P. \& Fellipe, G.M. 1999. Number of buried seeds and sedlings emergence in cerradão, cerrado and gallery forest soils at Pedregulho, Itirapina (SP), Brazil. Revista Brasileira de Botânica 22(2): 147-152.

Tan, K.H. 1996. Soil sampling, preparation and analisys. New York, Marcel Dekker. 